\title{
ASPECTO E COMPOSICIONALIDADE: UM OLHAR PARA OS ARGUMENTOS DO VERBO
}

\section{ASPECT AND COMPOSITIONALITY: A LOOK AT THE VERB ARGUMENTS}

\author{
Vanessa Escher Pagotto Ronchi ${ }^{1}$ \\ Universidade Federal de Viçosa (UFV) \\ Arabie Bezri Hermont ${ }^{2}$ \\ Pontifícia Universidade Católica de Minas Gerais (PUC Minas)
}

\begin{abstract}
RESUMO
O estudo do fenômeno aspectual no âmbito da composicionalidade, baseando-se na combinação do significado do verbo com seus argumentos, tem se mostrado relevante na atualidade. Nesse contexto, objetivou-se investigar, em sentenças do Português Brasileiro contemporâneo, se a natureza dos sintagmas nominais (argumentos internos e argumento externo) influencia a leitura aspectual do sintagma verbal e da sentença. Por uma abordagem qualitativa, foram analisadas 93 sentenças selecionadas de 52 notícias de jornais no período de dezembro de 2018 a junho de 2019 . Fundamentando-se em Verkuyl (1972, 1989, 1993, 2002), investigou-se o modo como as sentenças podem expressar diferentes formas de temporalidade, em termos da oposição aspecto terminativo/aspecto durativo. Das 93 ocorrências, 80 eram verbos achievements, seis eram verbos de atividade e sete eram verbos accomplishments. Em todas as sentenças com verbos achievements transitivos, houve alteração da interpretação aspectual em decorrência da natureza dos argumentos internos e externo. Situações apresentadas por verbos também achievements, porém intransitivos, fossem inergativos ou inacusativos, tiveram a terminatividade reforçada por complementos ocupando a posição do argumento interno. Com verbos de atividade e transitivos, houve modificação aspectual da situação, que passou a télica, devido à especificação dos argumentos internos e do argumento externo. Quando os verbos, apesar de indicarem atividade, eram inergativos, observou-se que, estando a posição do argumento interno ocupada, a situação passou a télica. Com verbos accomplishments, as situações apresentaram caráter durativo na presença de argumentos internos e argumento externo indeterminados. Concluiu-se que a natureza desses sintagmas nominais é fundamental no estudo do aspecto, devido à atualização no nível do sintagma verbal e no nível da sentença. Destacou-se na pesquisa o papel igualmente importante do argumento externo para a leitura aspectual, confirmando-se que, assim como postula Verkuyl, o limite superior do aspecto é o nível da sentença e não do verbo ou do sintagma verbal.
\end{abstract}

PALAVRAS-CHAVE: Aspecto. Composicionalidade. Argumento interno. Argumento externo.

\section{ABSTRACT}

The comprehension of the aspectual phenomenon concerning the compositionality, based on the association of the verb's meaning with its arguments, has become very important nowadays. Therefore, the goal of this project was to investigate, in contemporaneous Brazilian Portuguese sentences, if the nature of the noun phrases (inner and outer arguments) affects the aspectual reading of both the verb phrase and the sentence. Adopting a qualitative approach, 93 sentences extracted from 52 newspapers news were analyzed, from December 2018 to June 2019. Based on

\footnotetext{
1 Mestre em Linguística e Língua Portuguesa pela Pontifícia Universidade Federal de Minas Gerais. E-mail: escherv@yahoo.com.br.

2 Professora do Programa de Pós-Graduação em Letras da Pontifícia Universidade Federal de Minas Gerais. E-mail: arabie@uol.com.br.
} 
Verkuyl (1972, 1989, 1993, 2002), the way in which the sentences can express different types of temporality was investigated, in terms of the relationship of opposition between terminative and durative aspects. Among the 93 appearances, 80 were achievement verbs, six were verbs related to activity and seven were accomplishment verbs. In all the sentences containing transitive achievement verbs, alterations occurred in the aspectual interpretation owing to the nature of the inner and outer arguments. Situations presented by also achievement but intransitive verbs, being either not ergative or not accusative, had their terminativity stressed by complements occupying the inner argument position. With activity verbs and transitive verbs, aspectual changes of the situation were detected, which became telic, due to the specification of the inner and outer arguments. When the verbs were not ergative, even though they indicated activity, it was observed that when the inner argument position is occupied, the situation changed to telic. With accomplishment verbs, the situations started showing a durative character in the presence of inner and outer indeterminate arguments. Thus, it was concluded that the nature of these noun phrases is essential for aspect comprehension, owing to the change in the verb phrase's and the sentence's levels. It must be highlighted in this research, the equivalent importance of the outer argument's role in regard to the aspectual reading, confirming that, as stated by Verkuyl, the higher limit of the aspect is the sentence level, not the verb or verb phrase level.

KEYWORDS: Aspect. Compositionality. Inner argument. Outer argument.

\section{INTRODUÇÃO}

Tratar a aspectualidade com base na combinação dos significados do verbo com seus argumentos, em unidades maiores, é estudar o fenômeno aspectual no âmbito da composicionalidade. Dessa forma, para o desenvolvimento deste trabalho, assume-se, ancorandose em Verkuyl (1972, 1989, 1993, 2002), que o aspecto é uma propriedade linguística composicional, envolvendo não somente o verbo, mas também seus argumentos.

Propondo a distinção de três tipos situacionais: estados, processos e eventos, Verkuyl (1989, p. 79) afirma que foi desenvolvida a ideia de aspecto composicional, uma vez observado, em diversos trabalhos anteriores, que a interpretação por meio de uma "álgebra aspectual" no nível sintático desempenha papel fundamental na explicação do comportamento aspectual das sentenças.

Essa "álgebra", de acordo com Verkuyl (1989, p. 80), é sintática, na medida em que são constituintes sintáticos que carregam a informação semântica, ou seja, o comportamento aspectual das sentenças é explicado com o auxílio de dois parâmetros aspectuais, chamados de [ \pm ADD TO] ou $[ \pm$ dinâmico], para verbos, e de $[ \pm \mathrm{SQA}]$ ou $[ \pm$ específico], para seus argumentos.

Dessa forma, atribuindo valores positivos ou negativos quanto à dinamicidade dos verbos [ $\pm \mathrm{ADD}$ TO] e em relação à especificação/quantificação dos nomes [ $\pm \mathrm{SQA}]$, o autor demonstra, sintaticamente, que alterações no traço dessas características podem promover mudanças na interpretação aspectual da sentença, que alterna entre durativa e não durativa/terminativa, conforme se observa nos exemplos a seguir, extraídos de Verkuyl (1989, p. 79):

(1) She $[+\mathrm{SQA}]$ played $[+\mathrm{ADD} \mathrm{TO}]$ that sonata $[+\mathrm{SQA}]=$ terminative

Ela [+específico] tocou [+dinâmico] aquela sonata $[+$ específico $]=$ terminativa

(2) She [+SQA played [+ADD TO] sonatas [-SQA] = durative

Ela [+específico] tocou [+dinâmico] sonatas [-específico] $=$ durativa

(3) She $[+\mathrm{SQA}]$ bated $[-\mathrm{ADD} \mathrm{TO}]$ that sonata $[+\mathrm{SQA}]=$ durative

Ela [+específico] odiou [-dinâmico] aquela sonata [+específico] $=$ durativa

(4) She [+SQA] hated [-ADD TO] sonatas [-SQA] = durative

Ela [+específico] odiou [-dinâmico] sonatas [-específico] $=$ durativa

(5) Soldiers [-SQA] played [+ADD TO] that sonata [+SQA] $=$ durative 
Soldados [-específico] tocaram [+dinâmico] aquela sonata $[+$ específico $]=$ durativa

(6) Adults [-SQA] hated [-ADD TO] that sonata [+SQA] = durative

Adultos [-específico] odiaram [-dinâmico] aquela sonata [+específico] $=$ durativa

(7) Nobody [-SQA] hated [-ADD TO] sonatas [-SQA] = durative

Ninguém [-específico] odiou [-dinâmico] sonatas [-específico] $=$ durativa

(8) She [+SQA] didn't play $-[+\mathrm{ADD} \mathrm{TO}]$ that sonata $[+\mathrm{SQA}]=$ durative

Ela $[+$ específico $]$ não tocou $[-$ dinâmico $]$ aquela sonata $[+$ específico $]=$ durativa

Percebe-se que tanto o verbo quanto os sintagmas nominais são tomados como portadores aspectuais e que, para que o aspecto da sentença seja considerado terminativo, todos os seus elementos precisam ser positivos, o que implica dinamicidade ao verbo e especificação, determinação ou quantificação dos sintagmas nominais. Logo, a presença de verbos de estado, como "odiar", conforme mostrado no exemplo (3), ou a negação de uma ação, como em "não tocar", de acordo com o exemplo (8), são suficientes para caracterizar o aspecto durativo da sentença. Já em sentenças com verbos que envolvem mudança, como "tocar", apresentado nos exemplos (1), (2) e (5), é possível diferenciar sentenças durativas de terminativas pela análise dos argumentos do verbo.

Desse modo, por meio da investigação de sentenças do Português Brasileiro (PB) da contemporaneidade, em notícias de jornais, a proposta do presente trabalho foi verificar se a estrutura dos sintagmas nominais (argumentos internos e argumento externo) influencia a leitura aspectual do sintagma verbal e da sentença. O objetivo foi corroborar a ideia de que não se pode concluir a interpretação aspectual do sintagma verbal ou da sentença analisando-se apenas o verbo; é necessário que a análise vá para além dele, que se atente para seus argumentos internos e externo, numa perspectiva que contemple a relação entre todos os elementos da sentença, quer dizer, que o estudo do fenômeno aspectual seja realizado sob uma abordagem composicional.

\section{A classificação aspectual semântica}

Enquanto que o aspecto gramatical pode ser identificado pela flexão verbal, de acordo com o ponto de vista do falante, de forma perfectiva ou imperfectiva, como na oposição "Pedro caminhou" X "Pedro caminhava", as informações lexicais ou semânticas, propriedades inerentes aos itens lexicais, estão pressupostas no predicado verbal, como em: "Pedro estourou o balão" X "Pedro caminhou".

Assim, a despeito de ambas as formas serem perfectivas, a constituição temporal interna das situações é diferente. "Estourar" é um verbo que denota instantaneidade e "caminhar" indica um evento que transcorre por determinado período de tempo. Nesse sentido, essas situações, embora dinâmicas, podem ser distinguidas pela (a)telicidade ${ }^{3}$, isto é, observa-se um fim inerente ou pontualidade na situação expressa pelo verbo "estourar", mas não pelo verbo "caminhar", que indica situação com duração.

Conforme Wachowicz (2008, p. 60), a terminologia utilizada para as classes (aspectuais ou acionais), conhecida na tradição teórica por Aktionsarten, é explorada na literatura desde Vendler (1967), que "reinaugura as classes kinesis (processo) e energeia (ação), da tradição aristotélica, em quatro categorias ou classes aspectuais: estado, atividade, achievement e accomplishment".

De acordo com Vendler (1967, p. 26), verbos de estado ou estativos como "gostar", "amar", "ter" ou "desejar" indicam instantes de tempo num sentido indefinido; o conceito de atividade implica períodos de tempo indefinidos, ou seja, em que não se vê um fim inerente, como em "nadar", "correr" ou "caminhar"; achievements (ou culminações) denotam instantes de tempo definidos: "reconhecer", "vencer", "perder" e "encontrar" pertencem a essa classe; accomplishments

\footnotetext{
${ }^{3}$ O termo "télico" designa um limite temporal bem definido para a situação. A expressão "atélico", por sua vez, indica que não há limite temporal completamente definido para o evento.
} 
(ou processos culminados) indicam períodos de tempo definidos e, como exemplo, podem-se citar: "pintar um quadro", "construir uma casa", "escrever uma carta" e "fazer uma cadeira".

O aspecto lexical/semântico pode também ser evidenciado em sintagmas verbais, ou seja, observando-se a relação entre o verbo e seus complementos. Dessa forma, utilizando-se do mesmo exemplo, pode-se verificar a atualização do aspecto lexical/semântico quando se acrescenta à sentença "Pedro caminhou", o complemento "dois quilômetros". Se no primeiro exemplo ("Pedro caminhou") o verbo denota situação atélica, no segundo ("Pedro caminhou dois quilômetros"), a situação passa a ter um fim inerente, devido à característica telicizante do complemento.

Nessa direção, Smith (1997, p. 2) diz que o tipo de situação apresentado por uma sentença é transmitido pela constelação verbal, que ela define como um verbo principal e seus argumentos, incluindo o sujeito ${ }^{4}$. Tal assunto é mais bem explorado na seção seguinte.

\section{A composicionalidade e os argumentos internos e externo segundo Verkuyl}

A fim de demonstrar a natureza composicional do aspecto, Verkuyl (1972, p. IX) assinala que a seguinte fórmula pode ser aplicada:

${ }_{\mathrm{NP}}\left[\text { quantidade (in)específica de } \mathrm{X}^{5}\right]_{\mathrm{NP}}+{ }_{\mathrm{VP}}\left[\mathrm{v}[\mathrm{verbo}]_{\mathrm{V}}\left({ }_{\mathrm{NP}}[\text { quantidade (in)específica de } \mathrm{X}]_{\mathrm{NP}}\right)\right]_{\mathrm{VP}}$, em que:

$\mathrm{NP}=$ sintagma nominal

$\mathrm{VP}=$ sintagma verbal

$\mathrm{V}=$ verbo

Dessa forma, o autor esclarece que a atualização aspectual é dependente da especificação/quantificação dos sintagmas nominais sujeito (argumento externo) e objetos (argumentos internos) e conclui que é em S, conforme demonstrado na Figura 1, ou seja, no nível da sentença, onde ocorre o número mínimo de eventos, que se dá o limite superior do aspecto.

Figura 1 - Composição aspectual

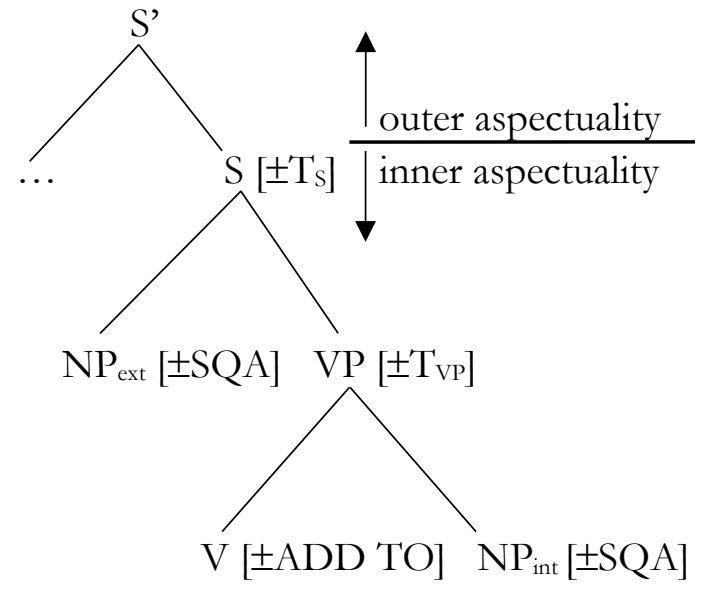

Fonte: Verkuyl (2002, p. 202)

\footnotetext{
4 Situation type is conveyed by the verb constellation, which I define as a main verb and its arguments, including subject (SMITH, 1997, p. 2).

${ }^{5}$ Embora o significado de X não esteja explicitado na fórmula, o autor o denomina de entidade (VERKUYL, 1972, p. 61).
} 
Constata-se, então, que existem dois níveis diferentes de estrutura envolvidos nesse processo. No primeiro, chamado inner aspectuality ou aspectualidade interna, ocorre a junção da informação do verbo (V) com o $\mathrm{NP}_{\text {int }}$ (sintagma nominal argumento interno) e a junção da informação do VP (sintagma verbal) com o NP ext (sintagma nominal argumento externo), formando a sentença. O segundo nível de estrutura está para além da sentença e é denominado outer aspectuality ou aspectualidade externa, onde estão alocadas informações adverbiais ou de contexto. Verkuyl diz que o estudo do aspecto interno concerne à relação entre o verbo e seus complementos e afirma que seu trabalho é crucialmente focado na composição desse aspecto.

A informação semântica associada ao verbo é nomeada [+ADD TO] e indica situação dinâmica e progressiva. A informação semântica associada aos argumentos do verbo é expressa por [+SQA] e indica uma quantidade específica de entidades introduzida pelo determinante (bead noun) do sintagma nominal. Essas informações são amalgamadas para a construção do aspecto terminativo (no nível do sintagma verbal $\left[+\mathrm{T}_{\mathrm{VP}}\right]$ e no nível da sentença $\left[+\mathrm{T}_{\mathrm{S}}\right]$ ).

Analisando os seguintes exemplos, extraídos de Verkuyl (2002, p. 204), onde $\mathrm{NP}_{2}=\mathrm{NP}_{\text {int: }}$ :

(9) Mary walked three miles. (Mary caminhou três milhas.) $=\mathrm{V}[+\mathrm{ADD} \mathrm{TO}]+\mathrm{NP}_{2}[+\mathrm{SQA}] \rightarrow$ $\left[+\mathrm{T}_{\mathrm{VP}}\right]=$ terminativo

(10) Mary walked miles. (Mary caminhou milhas.) $=\mathrm{V}[+\mathrm{ADD} \mathrm{TO}]+\mathrm{NP}_{2}[-\mathrm{SQA}] \rightarrow\left[-\mathrm{T}_{\mathrm{VP}}\right]=$ durativo

observa-se que o verbo tem o mesmo valor nas duas sentenças: [+ADD TO], e que é o complemento verbal que estabelece diferentes valores aspectuais aos dois [VPs]. O primeiro é $\left[+\mathrm{T}_{\mathrm{VP}}\right]$, ou seja, terminativo, e o segundo é [- $\left.\mathrm{T}_{\mathrm{VP}}\right]$, isto é, durativo.

Essa observação leva o autor a concluir que a informação semântica no nível VP difere da informação do nível inferior e que o $\mathrm{V}$ e o NP juntos formam uma informação diferente daquela estabelecida apenas pelo verbo.

Verkuyl (2002, p. 215) diz, ainda, que a natureza do argumento externo (NPext) pode alterar a terminatividade do VP, pelo que chama de Plus-Principle (Princípio Mais), cujo domínio natural parece ser o da aspectualidade interna. Segundo esse princípio, um valor negativo em qualquer nível abaixo da sentença é suficiente para produzir um valor durativo [-T] no topo da Figura 1. Assim, analisando o exemplo:

(11) [sNobody [vpwalked three miles] $]=$ [sNinguém [vpcaminhou três milhas]]

nota-se que o VP mantém sua propriedade terminativa $\left[+\mathrm{T}_{\mathrm{VP}}\right]$, mas, no nível $\mathrm{S}$, esse valor é neutralizado pela propriedade [-SQA] do argumento externo, resultando em [-TS , conforme esquema abaixo:

Figura 2 - Terminatividade da sentença

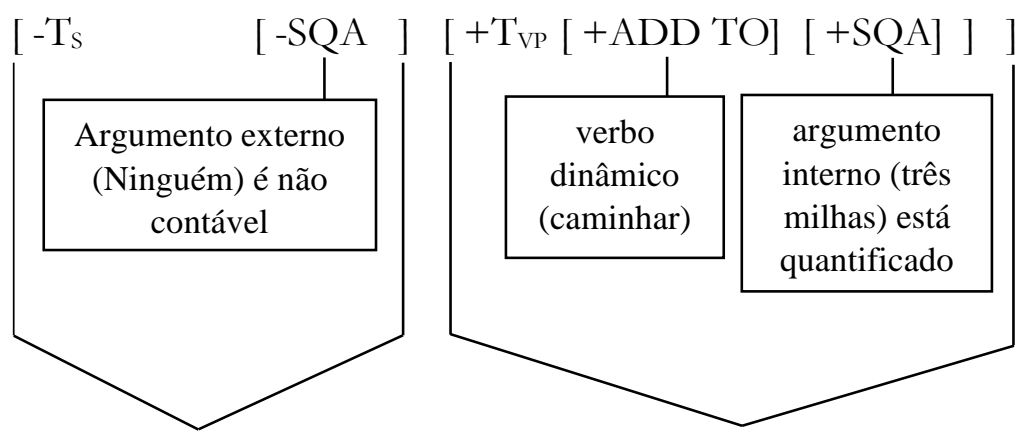


sentença (S) com propriedade sintagma verbal (VP) com propriedade não terminativa ou durativa terminativa ou não durativa

Fonte: Elaborado pelas autoras com base em Verkuyl (2002)

Ainda que de forma breve, o autor menciona que também o objeto indireto pode contribuir para a composição aspectual, sob condições apropriadas. Nesse sentido, a condição apresentada por ele para que haja o aspecto durativo é que ao menos uma das categorias: argumento externo/sujeito, argumento interno/objeto direto ou argumento interno/objeto indireto seja inespecífica. E, para que o aspecto seja considerado terminativo, é necessário que todas as categorias estejam especificadas.

Então, o mecanismo que está na base da composição do aspecto parece relativamente claro: uma certa subcategoria fundamental de um verbo (no caso, a dinamicidade, ou a não estatividade) é combinada com um conjunto complexo de categorias de natureza nominal e relativas à quantidade (VERKUYL, 1972, p. 98).

O autor salienta que o nó count (contável), ou seja, as categorias nas quais o count pode ser analisado, exerce um papel determinante na descrição do aspecto, pois o aspecto durativo ou não durativo pode ser parcialmente explicado pelas categorias massa/não contável e contável, assim, nomes como "mulher", "concerto", "poema" são chamados contáveis porque podem ocorrer com artigo indefinido ou elemento numérico: "um (qualquer um) poema" ou "dez poemas".

Destaque-se que o autor considera como elementos numéricos e, portanto, passíveis de serem quantificados, termos como "algum" e "alguns dos quais". Em trabalhos posteriores, é possível notar que ele utiliza os termos "quantificador" e "expressão quantificante" com referência a determinantes dessa natureza ${ }^{6}$.

A fim de expressar a ideia da composicionalidade, o autor demonstra, por meio das representações abaixo, retiradas de Verkuyl (1993, p. 20), que o aspecto terminativo pode ser visto como uma molécula construída pelos átomos [+ADD TO] e [+SQA] do verbo e de seus argumentos, respectivamente:

(12) Judith ate three sandwiches/Judith comeu três sanduíches $=$ [+SQA $]+[+\mathrm{ADD}$ TO $]+[+\mathrm{SQA}]$ $=[+\mathrm{T}]$

(13) Judith ate sandwiches/Judith comeu sanduíches $=[+\mathrm{SQA}]+[+\mathrm{ADD} \mathrm{TO}]+[-\mathrm{SQA}]=[-\mathrm{T}]$

(14) Judith ate no sandwich/Judith (não) comeu nenhum sanduíche $=[+\mathrm{SQA}]+[+\mathrm{ADD}$ TO] + $[-\mathrm{SQA}]=[-\mathrm{T}]$

(15) Judith wanted nothing/Judith (não) quis nada $=[+\mathrm{SQA}]+[-\mathrm{ADD} \mathrm{TO}]+[-\mathrm{SQA}]=[-\mathrm{T}]$

(16) Nobody ate a sandwich/Ninguém comeu um sanduíche $=[-\mathrm{SQA}]+[+\mathrm{ADD}$ TO $]+[+\mathrm{SQA}]=$ $[-\mathrm{T}]$

(17) Nobody ate sandwiches/Ninguém comeu sanduíches $=[-\mathrm{SQA}]+[+\mathrm{ADD} \mathrm{TO}]+[-\mathrm{SQA}]=[-\mathrm{T}]$

(18) Judith wanted a sandwich/Judith quis um sanduíche $=[+\mathrm{SQA}]+[-\mathrm{ADD} \mathrm{TO}]+[+\mathrm{SQA}]=[-\mathrm{T}]$

(19) No one wanted a sandwich/Nenhum ou Ninguém quis um sanduíche $=[-\mathrm{SQA}]+[-\mathrm{ADD} T \mathrm{TO}]+$ $[+\mathrm{SQA}]=[-\mathrm{T}]$

Observa-se que somente quando as características de todos os elementos (átomos) são positivas, a sentença (molécula composta) será terminativa, ou seja, $[+\mathrm{T}]$, assim, uma única característica negativa dos componentes (átomos) é suficiente para anular a terminatividade da sentença (molécula).

A fórmula trazida pelo autor mostra-se interessante para o desenvolvimento da proposta deste trabalho, pois importa ao objeto de pesquisa a observação quanto à

\footnotetext{
${ }^{6}$ A presença de elementos numéricos como dois, alguns, alguns dos quais etc. indica que o sintagma nominal se refere a entidades que podem ser quantificadas. Se esses elementos estiverem ausentes, simplesmente não podemos contar (VERKUYL, 1972, p. 61). [tradução nossa]
} 
especificação/quantificação do sintagma nominal na posição de argumento externo e dos sintagmas nominais na posição de argumento interno, visando verificar e compreender a implicação desses fatores para a atualização do aspecto.

\section{Expressões quantificadas, determinantes e traços semânticos: diferentes pontos de vista}

Considerando-se a importância da quantificação ou determinação para a atribuição do traço [ \pm SQA] aos sintagmas nominais, são analisados os posicionamentos de alguns autores nessa seção.

Verificando a sentença: "alguém é professor", Pires de Oliveira (2001, p. 180) diz que "alguém" é uma expressão complexa que comporta um quantificador, com a interpretação de "pelo menos um" e a propriedade de "ser pessoa". A autora diz, também, que operadores como "todos", "um", "algum", "dois" etc., são quantificadores, pois indicam quantos indivíduos de um certo tipo têm tal e tal propriedade, no caso de um predicado monoargumental, ou estabelecem tal ou tal relação com algum outro indivíduo, no caso de predicados de dois lugares.

Em se tratando de sentenças como "Alunos são inteligentes", em que o sintagma nominal aparece sozinho, sem qualquer determinante (são os chamados bare plurals ou plurais nus), Pires de Oliveira (2001, p. 206) diz que são perfeitamente compatíveis com "geralmente". As sentenças com plural nu, assim, estabelecem uma generalização: elas valem para a maioria dos elementos do seu domínio, mas não para todos.

O posicionamento de Pires de Oliveira (2001) quanto à generalização estabelecida por sentenças com plural nu vai ao encontro do que diz Verkuyl (1993), uma vez que, nesses casos, o sintagma nominal não está determinado, quantificado ou especificado, ou seja, é [-SQA], conforme classifica o autor, fator que caracteriza a genericidade do termo e a generalização da situação.

Para Verkuyl (1993, p. 98), também determinantes como "alguns", "poucos", "vários", "muitos" são [+SQA], apesar de serem considerados menos definidos que "o/a", "cada", "todo(s)", uma vez que a força (strenght) característica dos artigos e pronomes mais definidos [+definido] e a fraqueza (weakness) daqueles que são menos definidos [-definido] não coincide com a oposição entre [+SQA] e [-SQA].

Em Verkuyl (2002, p. 212), ressalta-se que [+SQA] não significa o mesmo que quantidade com cardinalidade ou medida identificada. $\mathrm{O}$ autor diz que muitos exemplos fornecem a quantidade exata, mas, na maioria dos casos, tem-se a informação de que há uma quantidade específica envolvida, mas não se conhece a cardinalidade ou a medida exata, como em: "Ela enviou muitas cartas" ou em "Ela bebeu um pouco de vinho", o que reforça seu posicionamento anterior.

Já Mollica (1977 apud GRYNER e OMENA, 2013, p. 94-95) diz que [+específico] e [+definido] caracterizam-se pela determinação: presença de artigo definido, demonstrativo e possessivo, ao passo que [-específico] e [-definido] pautam-se pela indeterminação: presença de artigo indefinido, pronome indefinido.

Um sintagma nominal como "alguns alunos", por exemplo, seria classificado como [determinado] ou [-específico] pela autora, devido à presença de um pronome indefinido, porém, para Verkuyl, o referido sintagma nominal seria considerado [+SQA], ou seja, quantificado, determinado, específico.

Do mesmo modo, expressões como "quase n", "pelo menos n" e "mais de n", em que n representa uma quantidade, e que são chamadas de "expressões quantificantes" por Verkuyl (1993, p. 102), são consideradas [+SQA] pelo autor.

Segundo Gryner e Omena (2013, p. 91), os traços semânticos mais frequentemente estudados foram agrupados em três blocos: 1) animacidade: [ \pm humano] e [ \pm animado]; 2) indeterminação: $[ \pm$ genérico], $[ \pm$ específico], $[ \pm$ determinado], $[ \pm$ definido], $[ \pm$ referente] e $[ \pm$ número de integrantes]; 3) atitude epistêmica ou "grau de certeza": [provável/possível].

Como a proposta deste trabalho comunga da perspectiva de Verkuyl $(1972,1989,1993$, 2002), serão analisados os traços $[ \pm$ nome], $[ \pm$ contável], $[ \pm$ comum $],[ \pm$ animado], $[ \pm$ humano $]$, de 
acordo com o que expõe Verkuyl (1972, p. 1). Nesse sentido, importa destacar que o traço [ \pm contável] corresponde à classificação $[ \pm \mathrm{SQA}]$, trazida pelo autor, e aos traços [ \pm determinado] e [tespecífico], propostos pelas autoras supramencionadas. Única ressalva é feita em relação ao traço [ \pm definido], tendo-se em vista que tal característica não coincide com $[ \pm \mathrm{SQA}]$, conforme explica Verkuyl (1993, p. 98), desse modo, determinantes constituídos por artigo indefinido, são considerados [+SQA] neste trabalho.

Sobre singulares nus ${ }^{7}$ e nomes massivos ${ }^{8}$, Bergantin (2018) e Pires de Oliveira e Rothstein (2011) concordam quanto à existência de um paralelismo em seu comportamento semântico e gramatical. Assim como o singular nu, determinantes/quantificadores gramaticalmente neutros para a distinção contável-massivo, como o quantificador de grau "muito" (no singular), podem exercer a função de expressar significado massivo, de acordo com esses autores.

Segundo Verkuyl (2002, p. 212), na maioria dos casos, tem-se a informação de que há uma quantidade específica envolvida, mas não se conhece a cardinalidade ou a medida exata. Assim, para o autor, mesmo quando se trata de termos massivos, como é o caso de "vinho" no exemplo "Ela bebeu um pouco de vinho", o valor [+SQA] deve ser atribuído ao sintagma nominal objeto direto "um pouco de vinho" pelo fato de ele estar especificado pela expressão "um pouco de".

A seguir, é apresentada a metodologia do trabalho.

\section{Metodologia}

Com o objetivo de verificar se a natureza dos argumentos internos e do argumento externo modifica a leitura aspectual, foram analisadas 93 sentenças selecionadas de 52 notícias dos seguintes jornais: Super Notícia e O Estadão, de Minas Gerais; A Gazeta, A Tribuna e Notícia Agora, do Espírito Santo; e Correio Brasiliense, do Distrito Federal, no período compreendido entre dezembro de 2018 e junho de 2019. A escolha dos jornais foi aleatória, na intenção de coletar exemplos diversificados, não tendo o estudo qualquer cunho sociolinguístico.

A pesquisa foi realizada por meio de testagens em relação às sentenças escolhidas, alterando-se as estruturas para verificar o que as mudanças provocavam. A abordagem do estudo, portanto, é qualitativa, em que o objetivo é a observação do comportamento.

Afinando-se à ideia de que "a conjectura ou a hipótese precede a observação ou percepção" e de que "todo aprendizado é uma modificação de algum conhecimento anterior" (POPPER, 1977 citado por MARCONI e LAKATOS, 2003, p. 97), optou-se pelo Método Hipotético-Dedutivo para o desenvolvimento desta pesquisa.

Partindo-se de algum conhecimento prévio ou expectativa, três etapas constituem o processo de investigação proposto pelo autor: a) problema - mostra o que é importante observar, quais dados devem ser selecionados; b) hipótese, conjectura e/ou suposição - é a proposição passível de teste, o que serve de guia para o pesquisador; c) tentativa de falseamento - são os testes de refutação realizados por meio de observação ou experimentação, entre outros.

Para o propósito do presente estudo, alinhado à perspectiva de Verkuyl (1972, 1989, 1993, 2002), apenas verbos dinâmicos interessaram à pesquisa, ou seja, aquelas ações que necessitam de um imput constante de energia para continuar acontecendo, ao contrário de verbos estativos.

Levando-se em conta, também, que a proposta apresentada por Verkuyl de análise da influência dos sintagmas nominais para a construção do aspecto terminativo ou durativo das sentenças utiliza exemplos em que a ação proposta pelo verbo é vista em seu todo, apenas sentenças

\footnotetext{
${ }^{7}$ Segundo Bevilaqua (2015 apud Bergantin, 2018), singular nu é um sintagma nominal desprovido de morfologia plural e também de determinantes.

${ }^{8}$ Conforme Bergantin (2018, p. 22), a massividade/incontabilidade é a ausência de quantificação em dimensão cardinal, pois se dá em dimensões não-cardinais, como massa, volume, intensidade etc.
} 
com verbos na forma perfectiva foram selecionadas, descartando-se as ocorrências de forma imperfectiva, que permite vislumbrar as fases internas de uma situação.

Considerando que "o perfeito representa a ação pura e simples, sem conotações adicionais" (COMRIE, 1976, p. 21) e que "o alcance semântico de verbos télicos é restringido consideravelmente quando combinados com o imperfectivo" (COMRIE, 1976, p. 46), a opção pelas formas perfectivas foi feita no intuito de reduzir as chances de interferência de outros fatores, que não a natureza dos argumentos do verbo, na interpretação da leitura aspectual.

Do mesmo modo, sentenças negativas não foram consideradas, tendo em vista que o aspecto é neutralizado pela negação da ação proposta pelo verbo, segundo afirma Verkuyl (1972, p. 106); a situação, nesse caso, é classificada como estado (VERKUYL, 2002, p. 207), portanto o verbo é [-ADD TO], ou seja, não dinâmico, fator que impossibilita a verificação da alteração do aspecto pelos argumentos do verbo da forma como o autor propõe. Percorreram-se, assim, os seguintes passos:

a) Identificaram-se, em notícias de jornal, sentenças que contivessem verbos de movimento ou não estáticos, conforme Verkuyl (1972, 1989, 1993, 2002);

b) Localizaram-se os verbos das sentenças e procedeu-se à sua classificação quanto ao aspecto lexical/semântico;

c) Identificaram-se os complementos verbais (argumentos internos) e verificou-se se a natureza de tais sintagmas nominais tem influência na alteração do aspecto lexical, por meio das características $[ \pm$ nome], $[ \pm$ contável], $[ \pm$ comum], $[ \pm$ animado] e $[ \pm$ humano];

d) Localizou-se o argumento externo da sentença e verificou-se se a sua natureza altera o aspecto lexical, por meio da observação das características [ \pm nome], $[ \pm$ contável], $[ \pm$ comum], [tanimado] e [thumano].

\section{Resultados}

Primeiramente, os verbos das sentenças extraídas das notícias foram classificados segundo a terminologia clássica proposta por Vendler (1967) para, em seguida, analisar a alteração promovida na leitura aspectual, em virtude da presença dos argumentos, conforme postulado por Verkuyl (1972, 1989, 1993, 2002). Assim, das 93 ocorrências encontradas, 80 eram verbos achievements, classificados no Quadro 1; seis eram verbos de atividade, apresentados no Quadro 2; e sete eram verbos accomplishments, conforme demonstrado no Quadro 3.

Quadro 1 - Verbos achievements

\begin{tabular}{|c|c|c|c|c|}
\hline $\begin{array}{c}\text { Classificação } \\
\text { Verbal }\end{array}$ & $\begin{array}{c}\text { Achievement } \\
\text { Transitivo Direto }\end{array}$ & $\begin{array}{c}\text { Achievement } \\
\text { Transitivo Direto } \\
\text { e Indireto }\end{array}$ & $\begin{array}{l}\text { Achievement } \\
\text { Inacusativo }\end{array}$ & $\begin{array}{l}\text { Achievement } \\
\text { Inergativo }\end{array}$ \\
\hline $\begin{array}{l}\text { Número de } \\
\text { ocorrências }\end{array}$ & 63 & 6 & 3 & 8 \\
\hline Verbos & $\begin{array}{c}\text { prender, cumprir, } \\
\text { interditar, quebrar, } \\
\text { ver }(2 \mathrm{x}) \text {, notificar, expedir, } \\
\text { nomear, emplacar, postar, } \\
\text { publicar, } \\
\text { acionar }(2 \mathrm{x}), \text { descobrir } \\
(2 \mathrm{x}), \\
\text { conquistar }(2 \mathrm{x}) \text {, ganhar, } \\
\text { encontrar, entregar, } \\
\text { encaminhar, trancar, }\end{array}$ & $\begin{array}{l}\text { enviar }(2 \mathrm{x}) \text {, } \\
\text { entregar, } \\
\text { apresentar, } \\
\text { repassar e } \\
\text { encaminhar }\end{array}$ & chegar $(3 \mathrm{x})$ & $\begin{array}{c}\text { entrar }(3 \mathrm{x}), \\
\text { fugir, votar, } \\
\text { estacionar, } \\
\text { candidatar-se e } \\
\text { disparar }\end{array}$ \\
\hline
\end{tabular}




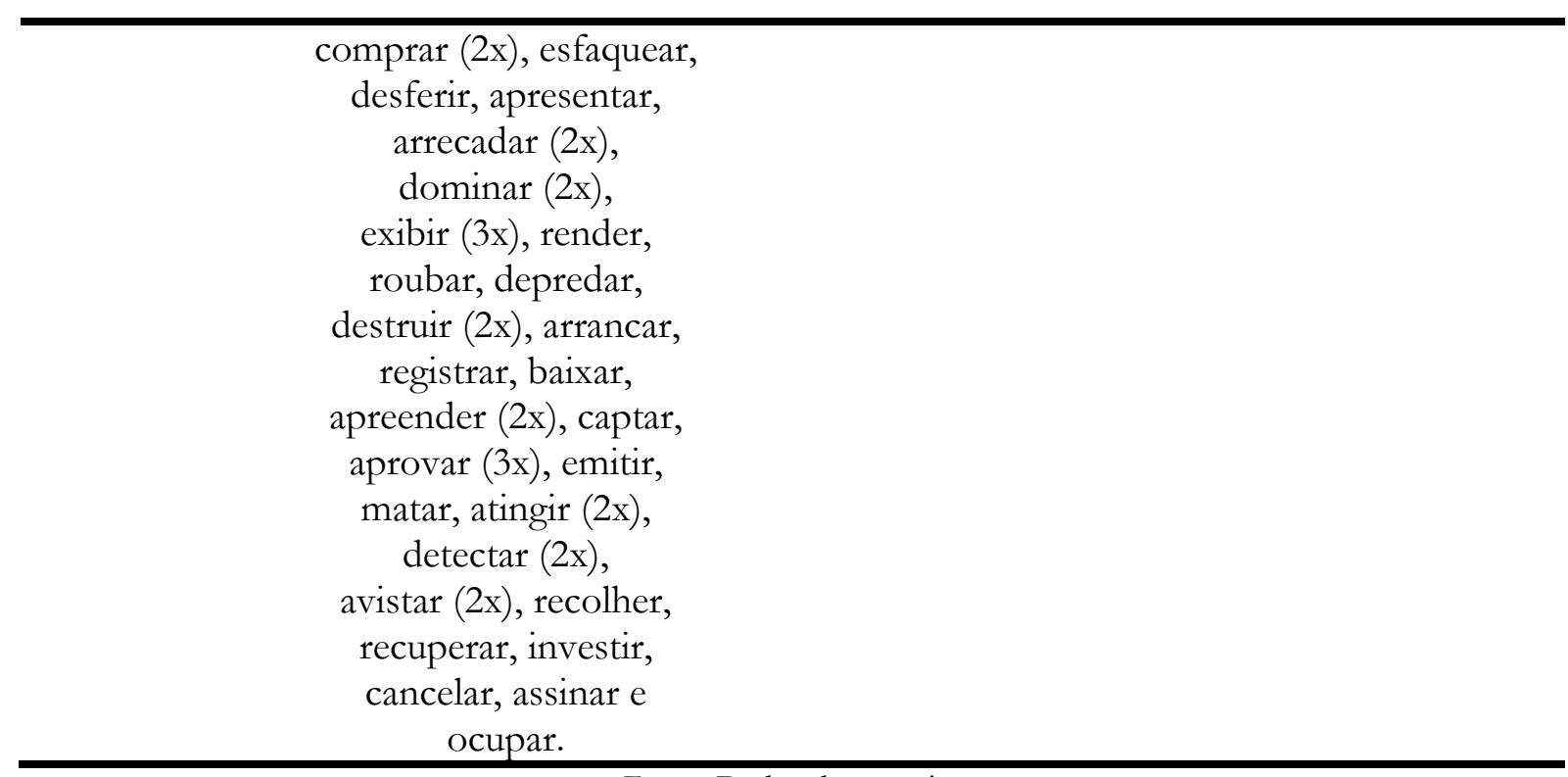

Fonte: Dados da pesquisa

Quadro 2 - Verbos atividade

\begin{tabular}{ccc}
\hline $\begin{array}{c}\text { Classificação } \\
\text { Verbal }\end{array}$ & $\begin{array}{c}\text { Atividade } \\
\text { Transitivo Direto }\end{array}$ & $\begin{array}{c}\text { Atividade } \\
\text { Inergativo }\end{array}$ \\
\hline $\begin{array}{c}\text { Número de } \\
\text { Ocorrências }\end{array}$ & 3 & 3 \\
\hline Verbos & procurar, puxar e levar & caminhar (2x) e trabalhar \\
\hline & Fonte: Dados da pesquisa & \\
\hline Qlassificação & Quadro 3 - Verbos accomplishments & Accomplishment \\
\hline Verbal & & Transitivo Direto \\
\hline Número de & & 7 \\
\hline Ocorrências & & \\
\hline Verbos & Fonte: Dados da pesquisa &
\end{tabular}

Em todas as sentenças com verbos achievements transitivos, foi possível observar alteração da interpretação aspectual, tanto no nível do sintagma verbal quanto no da sentença, em decorrência da natureza dos argumentos internos e externo, como mostra o exemplo a seguir:

(20) Uma megaoperação do Ministério Público em conjunto com a Polícia Civil e a Polícia Militar prendeu 18 pessoas e cumpriu 30 mandados de busca e apreensão por tráfico de drogas...

Note-se que tanto "prender" quanto "cumprir" são verbos dinâmicos e que apresentam aspecto terminativo, tratando-se de situações que têm um telos, ou seja, um fim, uma culminância. Atente-se, contudo, que o fato de os objetos estarem quantificados contribui para o sentido de término da situação.

(21) $\underline{\text { Uma megaoperacão }}[\ldots]$ prendeu $18 \underline{\text { pessoas } . . .}=[+\mathrm{SQA}]+[+\mathrm{ADD} \mathrm{TO}]+[+\mathrm{SQA}]=[+\mathrm{T}]$ 


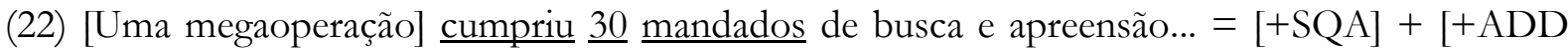
$\mathrm{TO}]+[+\mathrm{SQA}]=[+\mathrm{T}]$

Se o argumento interno não fosse determinado ou quantificado, veríamos a interpretação aspectual das sentenças se alterar:

(23) $[$ teste] Uma megaoperação prendeu pessoas... $=[+\mathrm{SQA}]+[+\mathrm{ADD} \mathrm{TO}]+[-\mathrm{SQA}]=[-\mathrm{T}]$

(24) $[$ teste] Uma megaoperação cumpriu mandados... $=[+\mathrm{SQA}]+[+\mathrm{ADD} \mathrm{TO}]+[-\mathrm{SQA}]=[-\mathrm{T}]$

A determinação ou a quantificação do argumento externo também pode influenciar na interpretação do aspecto:

(25) [teste] Megaoperação/Megaoperações do Ministério Público prendeu/prenderam 18 pessoas... $=[-\mathrm{SQA}]+[+\mathrm{ADD} \mathrm{TO}]+[+\mathrm{SQA}]=[-\mathrm{T}]$

Percebe-se que a indeterminação ou a falta de quantificação do sintagma nominal sujeito contribui para o aspecto durativo da sentença e que a leitura aspectual terminativa somente se mantém quando todos os elementos da sentença são positivos, quer dizer, se além de o verbo indicar movimento, os sintagmas nominais (sujeito ou complemento) forem determinados ou quantificados.

O plural nu em posição de sujeito (no caso, "Megaoperações") parece não deixar dúvidas com relação à contribuição de seu caráter indeterminado para o aspecto durativo da sentença, entretanto a sentença com o singular nu ("Megaoperação") ocupando essa posição não apresenta uma interpretação tão clara e natural, como propõem Pires de Oliveira e Rothstein (2011, p. 21602161).

Segundo as autoras, o singular nu pode ocorrer no caso de sentenças genéricas, mas não em frases episódicas, como em "Menino jogou bola". Elas explicam que a não naturalidade desse tipo de sentença se deve ao aspecto perfectivo do verbo, o que não ocorre em "Menino jogava futebol", em que o verbo está na forma imperfectiva.

Ainda que o singular nu em posição de sujeito fosse tratado como massivo, conforme é a proposta das autoras para o objeto direto, ele seria classificado como [-SQA] por Verkuyl, pelo fato de não estar especificado, o que, segundo o autor, caracteriza o aspecto da sentença como menos terminativo ou durativo.

Situações apresentadas por verbos também achievements, porém intransitivos, fossem inergativos ${ }^{9}$ ou inacusativos ${ }^{10}$, apesar de serem naturalmente télicas, tiveram a terminatividade reforçada por complementos ocupando a posição do argumento interno, como se observa nos exemplos seguintes:

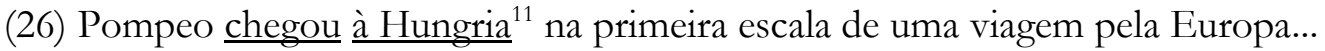

\footnotetext{
${ }^{9}$ Inergativos são verbos intransitivos ou monoargumentais que apresentam em sua estrutura apenas o argumento externo, deixando livre o lugar do argumento interno. São exemplos "entrar" e "fugir": "Pedro entrou."; "Pedro fugiu." ${ }^{10}$ Inacusativos são verbos intransitivos ou monoargumentais que apresentam em sua estrutura apenas o argumento interno, que transita na sentença para o lugar do argumento externo. Como exemplo, tem-se "chegar": "A carta chegou."; "Chegou a carta."

${ }^{11}$ Para os casos dos complementos em (26) e (27), os quais, em uma gramática normativa, seriam classificados como adjuntos adverbias, consideramo-los complementos adverbiais, associando-nos a um raciocínio similar ao de Saraiva (1983), para a qual há verbos que requerem complementos de tal natureza.
} 
(27) ... mais de 150 mil venezuelanos entraram no Brasil fugindo da hiperinflação, da escassez e da violência.

Observa-se que "chegar", e "entrar" são verbos que não necessariamente precisam de complemento, sendo perfeitamente possível dizer: "Pedro chegou." e "Pedro entrou." Independentemente do complemento verbal, tanto no nível do sintagma verbal quanto no nível da sentença, o aspecto permanece terminativo. A presença de complementos determinados apenas reforça essa terminatividade, comparem-se:

(28) [teste] $\underline{\text { Pompeo }} \underline{\text { chegou. }}=[+\mathrm{SQA}]+[+\mathrm{ADD} \mathrm{TO}]=[+\mathrm{T}]$

(29) $\underline{\text { Pompeo chegou à Hungria.... }}=[+\mathrm{SQA}]+[+\mathrm{ADD} \mathrm{TO}]+[+\mathrm{SQA}]=[+\mathrm{T}]$

(30) $[$ teste] ... mais de 150 mil venezuelanos entraram. $=[+\mathrm{SQA}]+[+\mathrm{ADD} \mathrm{TO}]=[+\mathrm{T}]$

(31) ... mais de 150 mil venezuelanos entraram no Brasil $\ldots=[+\mathrm{SQA}]+[+\mathrm{ADD} \mathrm{TO}]+[+\mathrm{SQA}]=$ $[+\mathrm{T}]$

Ainda que verbos inacusativos possuam apenas argumento interno, é mais natural, em sentenças da língua portuguesa, que ele ocupe a posição do argumento externo, deixando livre o lugar do argumento interno. Dessa forma, quando se analisam sentenças como "Pompeu chegou à Hungria", nota-se que o complemento "à Hungria", por estar no local original ou padrão do argumento interno, reforça o sentido télico já presente no verbo.

Vale ressaltar, ainda, que, nos dois exemplos, o argumento externo contribui para a terminatividade da sentença, tendo em vista sua especificação. Atente-se para o sintagma nominal "Mais de 150 mil venezuelanos...". Observa-se, nesse caso, o que Verkuyl (1993, p. 102) chama de expressão quantificante, assim, "mais de n", em que n representa uma quantidade, da mesma forma que nas expressões "pelo menos n" e "quase n", é considerada [+SQA].

É fato que, em perspectiva composicional, a terminatividade presente na raiz de verbos achievements contribui para a telicidade do sintagma verbal e da sentença; é preciso observar, todavia, que a análise pode divergir quando os verbos, embora achievements, são inergativos, inacusativos ou apresentam transitividade.

Em exemplos que continham verbos que denotam atividade, isto é, atélicos por essência, e transitivos, também se observou modificação aspectual da situação, que passou a télica, devido à determinação, especificação ou quantificação dos sintagmas nominais:

(32) $\underline{\text { Eles }}$ (os assaltantes) levaram minha bolsa... $=[+\mathrm{SQA}]+[+\mathrm{ADD} \mathrm{TO}]+[+\mathrm{SQA}]=[+\mathrm{T}]$

Assim, o fato de o argumento interno e o externo estarem determinados contribui para a terminatividade do sintagma verbal e da sentença, respectivamente. Observe-se a alteração aspectual quando da indeterminação de um ou outro argumento:

(33) $[$ teste $] \underline{\text { Eles }}$ (os assaltantes) levaram $\underline{\text { bolsas } . . . ~}=[+\mathrm{SQA}]+[+\mathrm{ADD} \mathrm{TO}]+[-\mathrm{SQA}]=[-\mathrm{T}]$

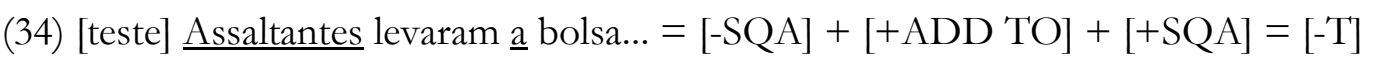

No primeiro caso, a indeterminação do argumento interno é responsável pelo aspecto não terminativo do sintagma verbal e, no segundo, o argumento externo não quantificado contribui para a duratividade no nível da sentença. Verifica-se que o nome "bolsa" apresenta os traços [+nome], [+contável], [+comum], [-animado], [-humano] e que "assaltantes" diferencia-se dele apenas por ser [+animado] e [+humano], evidenciando-se a relevância do traço [ \pm contável] para a descrição do aspecto, conforme aponta Verkuyl (1972, p. 98). 
Nos casos em que os verbos, apesar de indicarem atividade, eram inergativos, notou-se que, estando a posição do argumento interno ocupada, foi dado um ponto final na situação, que passou a télica ou terminativa, mudando, inclusive, a transitividade:

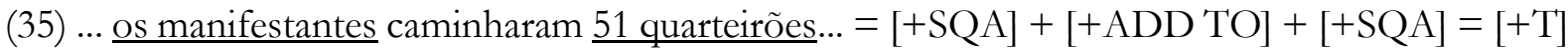

Note-se que "caminhar", como inergativo, ou seja, como verbo que seleciona apenas um argumento, o externo, não necessariamente requer um complemento, sendo perfeitamente aceitável a sentença: "Os manifestantes caminharam". Assim como ocorre com verbos de atividade como "andar", "correr", "nadar", ao se estipular um complemento para "caminhar", ocupa-se a posição do argumento interno e finda-se efetivamente o processo, trazendo à tona a telicidade do evento.

Tradicionalmente, "andar" ou "caminhar", verbos de atividade, apresentam caráter atélico, ou seja, descrevem um evento que não tem um fim inerente. A leitura aspectual passa a ter outra interpretação quando se insere um complemento que delimita o evento. Parece que, mesmo para o caso de verbos que selecionam apenas o argumento externo, quando se insere um complemento na posição do argumento interno, estabelece-se a constelação verbal mencionada por Smith (1997, p. 2) e torna-se possível analisar o fenômeno aspectual no escopo da aspectualidade interna, proposta por Verkuyl $(1972,1989,1993,2002)$.

Assim, ainda que se trate de uma modificação causada por uma expressão adverbial, o que, segundo o autor, estaria no âmbito da aspectualidade externa, o fato de o complemento ocupar a posição do argumento interno o torna passível de estudo sob a aspectualidade interna.

Acredita-se que isso explique o fato de tais casos serem contemplados pelo autor em seus estudos, como em: "Mary walked three miles", isto é, "Mary caminhou três milhas." (VERKUYL, 2002, p. 204), em que se tem um complemento para "caminhar", verbo de atividade e inergativo, isto é, que não seleciona argumento interno.

Recorde-se que Verkuyl (1993, p. 14) menciona a diferença entre inner e outer aspectuality (aspecto interno e externo, respectivamente) e diz que o estudo do aspecto interno (grifo nosso) concerne à relação entre o verbo e seus complementos (grifo nosso), afirmando que seu trabalho é crucialmente focado na composição desse aspecto.

É importante notar, entretanto, que a quantificação do sintagma nominal sujeito da sentença pode interferir na leitura aspectual da sentença, corroborando a argumentação de Verkuyl (1972, 1989, 1993, 2002), o que pode ser constatado comparando-se o exemplo (35) com o seguinte, em que a indeterminação do argumento externo contribui para a duratividade da sentença:

(36) $[$ teste] $\ldots$ manifestantes caminharam 51 quilômetros... $=[$-SQA $]+[+\mathrm{ADD}$ TO $]+[+\mathrm{SQA}]=$ $[-\mathrm{T}]$

Os exemplos com verbos accomplishments mostraram que as situações colocadas por esses verbos, que carregam o sentido télico na raiz, uma vez que indicam um período de tempo com limite definido, apresentam caráter durativo na presença de sintagmas nominais indeterminados:

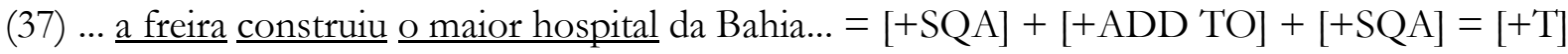

(38) $[$ teste $] \ldots \underline{\text { a freira construiu hospitais. }}=[+\mathrm{SQA}]+[+\mathrm{ADD} \mathrm{TO}]+[-\mathrm{SQA}]=[-\mathrm{T}]$

(39) [teste] $\ldots \underline{\text { freiras }} \underline{\text { construíram }} \underline{\text { o hospital. }}=[-\mathrm{SQA}]+[+\mathrm{ADD}$ TO $]+[+\mathrm{SQA}]=[-\mathrm{T}]$

Os verbos accomplishments, assim como os achievements, apresentam um fim inerente, porém, ao contrário desses, que são caracterizados pela instantaneidade, aqueles indicam um processo até 
que se chegue ao ponto de culminância. Na presença de um argumento interno não especificado, o sintagma verbal e, consequentemente a sentença, tornam-se durativos [-T].

Pela segunda testagem, percebe-se que, mesmo que se mantenha o argumento interno determinado, gerando um sintagma verbal terminativo, se o argumento externo não for especificado, essa terminatividade é anulada no nível da sentença.

\section{CONSIDERAÇÕES FINAIS}

A proposta deste trabalho foi analisar o fenômeno aspectual sob perspectiva composicional, consultando-se não somente o verbo, mas também seus argumentos, no processo de interpretação. Para tanto, investigou-se, em sentenças do Português Brasileiro contemporâneo, se a natureza dos sintagmas nominais (argumentos internos e argumento externo) influencia a leitura aspectual do sintagma verbal e da sentença. Sob essa ótica, o aspecto é construído por meio da análise da informação semântica expressa pelos diferentes elementos sintáticos, especificamente o verbo e seus argumentos.

Para o desenvolvimento da pesquisa, fundamentou-se em Verkuyl (1972, 1989, 1993, 2002), para quem o modo como as sentenças podem expressar diferentes formas de temporalidade se dá, basicamente, em termos da oposição aspecto terminativo/aspecto durativo.

A análise da natureza dos sintagmas nominais nesta pesquisa mostrou que o traço [ \pm contável] é o de maior relevância para a verificação de modificações no fenômeno aspectual, confirmando o que postula Verkuyl $(1972,1989,1993,2002)$.

Também foi possível verificar que, nos casos em que o sintagma nominal singular ocorre desacompanhado de determinante, especificador ou quantificador, não fica tão nítida a noção de indeterminação e, portanto, de duratividade ocasionada por esse termo. Embora o singular nu não seja determinante para a seleção de uma interpretação contável ou massiva, concorda-se com Bergantin (2018) e Pires de Oliveira e Rothstein (2011), para quem o singular nu é mais utilizado para expressar massividade. Dessa forma, sendo o termo considerado massivo, é desprovido de especificação e, portanto, classificado por Verkuyl de [-SQA], o que caracteriza o aspecto menos terminativo $[-\mathrm{T}]$ do sintagma verbal e, consequentemente, da sentença.

A dificuldade em perceber a noção de indeterminação do sintagma nominal singular nu ficou mais evidente para o argumento externo, como no exemplo "Megaoperação prendeu 18 pessoas", em que a falta do determinante não parece ocasionar diminuição tão acentuada da terminatividade aspectual quanto nos casos em que o termo aparece sozinho, sem qualquer determinante, porém pluralizado, como em "Megaoperações prenderam 18 pessoas".

Dessa forma, a sentença com o singular nu ocupando a posição de sujeito não apresenta uma interpretação tão clara e natural quanto aquela com o plural nu. Isso vai ao encontro do posicionamento de Pires de Oliveira e Rothstein (2011), que argumentam que o singular nu em posição de sujeito impossibilita uma leitura natural quando o verbo está na forma perfectiva, o que não ocorre quando o aspecto verbal é imperfectivo, situação apresentada como genérica pelas autoras.

Ainda que o singular nu em posição de sujeito fosse tratado como massivo, conforme é a proposta das autoras para o objeto direto, ele seria classificado como [-SQA] por Verkuyl, pelo fato de não estar especificado, o que, segundo o autor, caracteriza o aspecto da sentença como menos terminativo ou durativo.

Já com relação ao plural nu, parece não haver dúvidas. Pires de Oliveira (2001, p. 206) destaca sua natureza indeterminada ou generalizada, dizendo que sentenças com esses termos estabelecem generalização, opinião compartilhada por Verkuyl. Devido à ausência de determinação, quantificação ou especificação do plural nu, Verkuyl classifica-o como [-SQA] e demonstra que esse fator contribui para o aspecto durativo da sentença, o que pôde ser verificado nos resultados deste trabalho. 
Nesse sentido, especialmente com relação ao argumento externo, conclui-se que o caráter [-T] ou durativo da sentença é observado claramente nos casos em que o sintagma nominal ocorre pluralizado e desacompanhado de determinante, isto é, a falta de especificação de um nome pluralizado não deixa dúvidas quanto à classificação [-SQA] atribuída ao sintagma nominal e à leitura durativa do sintagma verbal e da sentença. Quando se trata de elemento no singular, embora a ausência do determinante não provoque alteração tão nítida na leitura aspectual, entende-se que há contribuição desse fator para a duratividade da situação, conforme propõe Verkuyl.

Os resultados encontrados comprovam a relevância da perspectiva composicional para o estudo do aspecto, uma vez que o resultado da análise no nível do sintagma verbal e no nível da sentença é diferente de quando se verifica apenas a informação semântica contida no verbo. Demonstrou-se que a correta classificação aspectual passa pela observação não somente do verbo, mas pela análise conjunta do verbo com seus argumentos, e que influencia de maneira substancial nessa leitura a natureza dos sintagmas nominais, por meio da observação de seu determinante.

Dessa forma, corrobora-se a colocação de Verkuyl (1972, p. 98) de que o limite superior do aspecto é o nível da sentença e não do verbo ou do sintagma verbal, uma vez que, ainda que o sintagma verbal mantenha sua propriedade terminativa $\left[+\mathrm{T}_{\mathrm{VP}}\right]$, esse valor é neutralizado pela propriedade [-SQA] do argumento externo, resultando em uma sentença com propriedade não terminativa $\left[-\mathrm{T}_{\mathrm{S}}\right]$.

Levando-se em conta que as pesquisas sobre aspecto no âmbito da composicionalidade são predominantemente direcionadas ao verbo, argumentos internos e adjuntos, importa destacar que, neste trabalho, o papel do argumento externo se mostrou igualmente relevante para a atualização do aspecto, o que nos permite vislumbrar um campo de análise a ser levado em consideração em trabalhos futuros.

\section{REFERÊNCIAS}

BERGANTIN, Lucas Bueno. Expressão nominal massiva e contável em português brasileiro. 2018, 187 f. Dissertação (Mestrado) - Universidade Federal de São Carlos, Programa de Pós-Graduação em Linguística. São Carlos, 2018.

COMRIE, Bernard. Aspect: an introduction to the study of verbal aspect and related problems. New York: Cambridge University Press, 1976.

GRYNER, Helena; OMENA, Neliza Pereira. A interferência das variáveis semânticas. In: MOLLICA, M. C.; BRAGA, M. L. Introdução à sociolinguística: o tratamento da variação. 4. ed. 2. re. São Paulo: Contexto, 2013, p. 89-100.

LAKATOS, Eva Maria; MARCONI, Marina de Andrade. Fundamentos de Metodologia Científica. 5. ed. São Paulo: Atlas, 2003.

PIRES DE OLIVEIRA, Roberta. Semântica formal: uma breve introdução. Campinas, SP: Mercado das Letras, 2001.

PIRES DE OLIVEIRA, Roberta; ROTHSTEIN, Susan. Bare singular noun phrases are mass in Brazilian Portuguese. Língua, v. 121, n.15, p. 2153-2175, 2011.

SARAIVA, Maria Elizabeth Fonseca. Verbo "Transitivo Adverbial” - Uma mera questão de rótulo? Belo Horizonte: Revista de Estudos Românicos, n. 2, p. 117-124, 1983. 
SMITH, Carlota. The Parameter of Aspect. Studies in Linguistics and Philosophy, v. 43. Dordrecht: Kluwer Academic Publishers, 1997.

VENDLER, Zeno. Verbs and Times. In: . Linguistics in Philosophy. Ithaca. NY: Cornell University Press, 1967, p. 1-32.

VERKUYL, Henk J. On the compositional nature of the aspects. FLSS, v. 15. Dordrecht: D. Reidel Publishing Company, 1972.

Aspectual classes and aspectual composition. Linguistics and Philosophy, Dordrecht, v. 12, p. 39-94, 1989.

A theory of aspectuality: the interaction between temporal and atemporal structure. Cambridge Studies in Linguistics, v. 64. Cambridge: Cambridge University Press, 1993.

Aspectual composition: Surveying the ingredients. Utrecht Institute of Linguistics (OTS), p. 201-219, 2002.

WACHOWICZ, Teresa Cristina. Telicidade e classes aspectuais. Revista do GEL. São José do Rio Preto, v. 5, n. 1, p. 57-68, 2008.

Submetido em 22/01/2021

Aceito em 12/07/2021 